P0-0979 IMPROVING PATIENT SAFETY IN PAEDIATRIC HANDOVERS

M McGowan, AM McClean, R Verma, M Anandarajan. Paediatrics, Ulster Hospital, Belfast, UK

\subsection{6/archdischild-2014-307384.1596}

Background and aims The implementation of European working time directive and shift patterns of working has highlighted the importance of good handovers in Paediatrics. Current guidance from $\mathrm{RCPCH}$ and GMC stress the importance of good handovers. We present a closed loop audit cycle of handover practice, process mapping, the organisational strategies which resulted in use of standardised handover proformas, reducing potential for clinical errors and improved handovers in a district general hospital ( $\sim 4000$ paediatric inpatients a year).

Methods Data was collected assessing the handover process using 19 parameters, which included - timing, duration, structure, documentation, facilities and facets of clinical care, over a 2 week period. Changes were introduced following the audit and a re-audit was carried out with same parameters.

Results 604 patients were handed over in 2 weeks (32 handovers) during the initial audit. 69\% of handovers were delayed greater than $5 \mathrm{~min}$ and finished beyond the designated time on $50 \%$ occasions. Average duration was 25 mins with 17 interruptions during 2 week period.

Changes were implemented following the audit, which involved organisational strategies:

Safety briefing

Handover proceedings sheet

Structured handover sheet

Training sessions

SBAR handover tool

Bleep free period for handover (except emergencies)

The re-audit showed significant improvement in all parameters monitored and resulted in improved patient safety and quality of care.

Conclusions The use of structured handover format and the above organisational strategies has resulted in improvement in the efficacy and efficiency of data transfer during patient handover and good clinical documentation, resulting in improved patient safety and quality of care.

\section{PO-0980 STIGMA AND PARENTAL HELP-SEEKING FOR CHILD BEHAVIOUR PROBLEMS: COMPARISON BETWEEN URBAN AFRICAN AMERICAN AND RURAL EUROPEAN AMERICAN PARENTS IN THE UNITED STATES}

${ }^{1} \mathrm{D}$ Davis, ${ }^{2} \mathrm{R}$ Dempster, ${ }^{1} \mathrm{VF}$ Jones, ${ }^{3} \mathrm{~B}$ Wildman, ${ }^{4} \mathrm{~A}$ Keating. ${ }^{1}$ Pediatrics, University of Louisville, Louisville, USA; ${ }^{2}$ Pediatrics, Nationwide Children's Hospital, Columbus, USA; ${ }^{3}$ Psychology, Kent State University, Kent, USA; ${ }^{4}$ Pediatrics, Cleveland Clinic, Cleveland, USA

\subsection{6/archdischild-2014-307384.1597}

Objective Significant numbers of U. S. children have diagnosable mental health problems, but only a small proportion of them receive appropriate services. The current study aims to understand factors, including stigma, associated with parents' helpseeking behaviour related to child behaviour problems and to determine if there are cultural differences in those factors.

Method Participants were the parents and/or legal guardians of children ages 3-8 years recruited from primary care settings in 2 locations within the U. S. One group was Caucasian $(\mathrm{n}=128)$ from a rural area and one group was African American $(\mathrm{n}=$ 101) from an urban location. Variables included child behaviour, stigma (self, friends/family, and public), object of stigma (parent or child), obstacles for engagement, intention to attend parenting classes, sources of and preferences for parenting advice, and demographics.

Results Parents perceive stigma associated with child behaviour problems and there were differences between the groups on the types of stigma, the object of the stigma, and the relationships to help-seeking. Group differences were also found regarding the sources of and preferences for parenting advice.

Conclusions Parent stigma should be considered in the design of care models to ensure that children receive appropriate and timely preventative and treatment services for behavioural/mental health problems.

\section{PO-0981 A NOVEL MUTATION OF IPEX SYNDROME IN A PAEDIATRIC PATIENT}

${ }^{1} \mathrm{D}$ Rallis, ${ }^{1} \mathrm{~F}$ Yfanti, ${ }^{1} \mathrm{~A}$ Taliou, ${ }^{1} \mathrm{~S}$ Kouni, 'V Pantelaros, ${ }^{2} \mathrm{M}$ Kanariou, ${ }^{1} \mathrm{I}$ Orfanou, ${ }^{1} \mathrm{E}$ Botsa. ${ }^{1}$ Paediatrics, Aghia Sophia Children's Hospital, Athens, Greece; ${ }^{2}$ ImmunologyHistocompatibility, Aghia Sophia Children's Hospital, Athens, Greece

\subsection{6/archdischild-2014-307384.1598}

Background Immunodysregulation, polyendocrinopathy, enteropathy, X-linked (IPEX) syndrome is a rare disorder characterised by multiple autoimmunity. Mutations in the fork head box P3 (FOXP3) gene, in chromosome Xp11.23, result in reduced numbers or a complete absence of $\mathrm{CD}^{+}{ }^{+}$regulatory $\mathrm{T}$ (Treg) cells and therefore in a variety of clinical presentation.

Methods We present the case of a 3-year old male with clinical and laboratory findings of IPEX and a novel mutation of the FOXP3 gene.

Results A 3-year Chinese male was admitted to the 3rd Clinic of the First Paediatrics of University of Athens, Greece, due to critical malnutrition. Severe diarrhoea and malabsorption were the predominant symptoms; therefore the administration of long term TPN was essential. The patient underwent a colonoscopy which revealed autoimmune enteropathy, while Diabetes type I, the other major clinical finding, required strict dietary program and insulin administration. Our patient was set on steroids and azathioprine, which was withdrawn however due to cholestasis on day 107.

Patient's laboratory findings were constant with immunodeficiency (low immunoglobulins IgA and IgM), nevertheless, the flow cytometry revealed normal number of $\mathrm{CD} 4^{+} / \mathrm{CD} 25^{+}$regulatory cells.

Under the strong suspicion of IPEX syndrome, a molecular analysis was performed and a novel mutation, c.1161G-p. H387Q in FOXP3 gene was identified, confirming the diagnosis. Conclusions A total of 13 allelic variants in FOXP3 have been described so far, leading into different phenotypes of IPEX syndrome. The genetic variant c.1161G has been associated with hepatocellular carcinoma in Chinese population, but has never been reported in IPEX syndrome.

\section{PO-0982 THE IMPACT AND IMPORTANCE OF EARLY DIAGNOSIS OF POSTERIOR ANKYLOGLOSSIA: A CASE SERIES}

NJ Oakley, C Kallappa. Department of Paediatrics, Good Hope Hospital, Birmingham, UK

10.1136/archdischild-2014-307384.1599 